\section{Case Reports in Neurology}

Case Rep Neurol 2020;12:440-446

DOI: 10.1159/00051120

Published online: November 17, 2020 (c) 2020 The Author(s)

Published by S. Karger AG, Basel www.karger.com/crn

This article is licensed under the Creative Commons Attribution-NonCommercial 4.0 International License (CC BY-NC) (http://www.karger.com/Services/OpenAccessLicense). Usage and distribution for commercial purposes requires written permission.

\title{
Reversible Cerebral Vasoconstriction Syndrome after Nifedipine Withdrawal
}

\author{
Mohammed H. Alanazy ${ }^{a} \quad$ Ali Alwadei $^{b} \quad$ Zaid F. Alsaaran $^{a}$ \\ Fahad A. Essbaiheen ${ }^{c}$ \\ aDepartment of Internal Medicine, College of Medicine, King Saud University, \\ Riyadh, Saudi Arabia; ${ }^{b}$ Department of Neurosurgery, College of Medicine, Imam \\ Abdulrahman Bin Faisal University, Dammam, Saudi Arabia; 'Department of Medical \\ Imaging, College of Medicine, King Saud University, Riyadh, Saudi Arabia
}

\section{Keywords}

Reversible cerebral vasoconstriction syndrome · Nifedipine · Subarachnoid haemorrhage · Thunderclap headache

\section{Abstract}

Reversible cerebral vasoconstriction syndrome (RCVS) is an essential but often unrecognized cause of intracranial haemorrhage. While there are no specific causes of the syndrome, associations with many clinical conditions and drugs have been observed, and calcium channel blockers (CCBs) are often used to relieve the symptoms. This is a case of RCVS that was triggered by the sudden withdrawal of nifedipine, a CCB.

\section{Introduction}

Reversible cerebral vasoconstriction syndrome (RCVS) is characterized by recurrent episodes of thunderclap headaches (TCHs) and multifocal reversible vasoconstriction and dilatation in cerebral arteries $[1,2]$. RCVS can develop either spontaneously or secondary to various conditions [3, 4]. Despite the occurrence of RCVS over a wide range of ages, it has been observed that spontaneous RCVS is more predominant in women than secondary RCVS, in 


\section{Case Reports in Neurology}

Case Rep Neurol 2020;12:440-446

DOI: 10.1159/000511204

(c) 2020 The Author(s). Published by S. Karger AG, Basel www.karger.com/crn

Alanazy et al.: Reversible Cerebral Vasoconstriction Syndrome after Nifedipine Withdrawal

which the gender split is less significant [3,5-8]. RCVS patients often present with a headache due to the innervation of cerebral blood vessels with sensory afferents from the trigeminal nerve (V1) and the dorsal root of C2 [2]. Nonetheless, recent evidence reported that calcium channel blockers (CCBs) could relieve the symptoms of RCVS [6, 9].

\section{Case Presentation}

A 53-year-old Asian female nurse presented to the emergency department with a TCH. The patient had stopped nifedipine, which she had been using as a treatment for hypertension (HTN), 1 week earlier due to lower limb oedema. The headache was sudden and intensified to the worst headache she had ever experienced within 1 minute. Her headache was holocephalic, constant and pulsatile and radiated to the neck. She also had nausea, dizziness, photophobia, and left upper extremity heaviness. There was no history of fever, dysarthria, paraesthesia, loss of consciousness, seizure, visual disturbance or auditory symptoms. She had no previous history of migraine. She denied recent neck trauma or chiropractic manipulation. She did not smoke or drink alcohol. The family history was negative for polycystic kidney disease, stroke and sudden death.

The past history included a 10-year history of HTN that was controlled on a treatment regimen of $60 \mathrm{mg}$ nifedipine and $150 \mathrm{mg}$ irbesartan daily. She had hypothyroidism, inflammatory arthritis (undifferentiated), and latent tuberculosis. In addition to antihypertensives, she took isoniazid and L-thyroxine. The past surgical history was significant for total thyroidectomy for a goitre.

Upon examination, she was conscious, cooperative and oriented to time, person and place. Her blood pressure (BP) was 158/94 mm Hg, her heart rate was $91 \mathrm{bpm}$, she was afebrile with a temperature of $36.8^{\circ} \mathrm{C}$, and her respiratory rate was $20 / \mathrm{min}$. Her pupils were bilaterally equal and reactive. There was no optic disc oedema, visual field defect or facial asymmetry. She had a normal range of extra-ocular movements. The tongue and palate were normal and symmetric. Muscle tone, power and reflexes were normal. She had equal and intact sensation perceptions of pinprick, vibration and proprioception bilaterally. There were no cerebellar signs. Her gait was normal. She did not have any difficulty in flexion or extension of the neck but experienced pain on sideward movements.

In the ER, a head computed tomography (CT) scan was normal. The CT angiogram of the head and neck was normal. The patient was admitted for further workup and pain control. A CT head after $48 \mathrm{~h}$ revealed frontoparietal and right frontal convexal subarachnoid haemorrhage (SAH) with mild cortical swelling (Fig. 1a). Brain magnetic resonance imaging (MRI) revealed T2 and fluid-attenuation inversion recovery patchy areas of subarachnoid space signal abnormalities involving the bilateral frontoparietal and, to a lesser extent, occipital areas, with blooming on the susceptibility-weighted images (Fig. 1b-d). Focal areas of enhancement could not be determined due to the masking effect of subarachnoid blood. Our initial differential diagnoses were metastatic lesions and an infection secondary to tuberculosis. A lumbar puncture was then performed to rule out infectious causes. Cerebrospinal fluid analysis revealed $0.60 \mathrm{~g} / \mathrm{L}$ protein, $4.18 \mathrm{mmol} / \mathrm{L}$ glucose (serum glucose $6.38 \mathrm{mmol} / \mathrm{L}$ ), 4,800/ $\mu \mathrm{L}$ red blood cells and $0 / \mu \mathrm{L}$ white blood cells. The cerebrospinal fluid appeared xanthochromic by visual inspection, although spectrophotometry was not available. CT of the chest, abdomen and pelvis showed no evidence of malignancy or lung tuberculosis.

On the 3rd day of admission, the patient developed right arm and leg weakness and numbness. The right upper limb Medical Research Council (MRC) score was 4/5, and the right lower 


\section{Case Reports in Neurology}

Case Rep Neurol 2020;12:440-446

DOI: $10.1159 / 000511204$

C 2020 The Author(s). Published by S. Karger AG, Basel www.karger.com/crn

Alanazy et al.: Reversible Cerebral Vasoconstriction Syndrome after Nifedipine Withdrawal

limb MRC score was 2/5, whereas the strength of the left upper and lower limbs was normal (5/5). Pinprick sensation was decreased on the right upper and lower limbs. Therefore, a decision was made to perform conventional cerebral angiography to rule out vasculitis and reversible vasoconstriction syndrome. Her angiogram showed multiple areas of arterial beadings in the anterior and posterior circulation, with interval improvement after injection of a verapamil (Fig. 2). She was given a total dose of $5 \mathrm{mg}$ verapamil distributed in the right internal carotid, left internal carotid and left vertebral arteries. The procedure was complicated by right vertebral artery dissection. After verapamil injection and before ending the procedure, her BP dropped, necessitating transient administration of vasopressors. Her headache improved significantly after the procedure. Head CT was repeated immediately after the procedure and did not show interval changes compared to baseline CT. Afterwards, the patient was moved to the intensive care unit for BP monitoring. She developed new-onset left internuclear ophthalmoplegia and mild upper limb dysmetria, but the right-side weakness did not worsen. She was started on aspirin and clopidogrel. Repeat brain MRI showed a wedge-shaped area of diffusion restriction in the distal right cerebellar hemisphere and scattered left parietal and occipital lobe diffusion restrictions consistent with small acute ischaemic insults, with a patent basilar artery. On the second day after the procedure, internuclear ophthalmoplegia improved with a residual adduction lag in the left eye.

After evaluating the patient for malignancy, autoimmune disorders and vasculitis, which were all negative, the patient was diagnosed with RCVS secondary to sudden nifedipine cessation. She was discharged home and seen in the clinic 2 weeks later; by then, her neurological examination had normalized.

\section{Discussion}

There is a growing body of evidence recognizing RCVS as an essential cause of intracranial haemorrhage [1]. RCVS has been reported in a wide range of ages, from 19 months to 70 years, with a mean age of presentation in the 4 th decade of life $[1,5,9]$. Women are affected more commonly than men $[3,6,7]$, with a ratio reaching $4: 1$ [9].

RCVS can occur spontaneously or secondary to other causes, which are identifiable in up to $80 \%$ of cases [8]. Some of these associated conditions include migraine [3, 4], complications due to neurological surgeries [10], hypertensive encephalopathy, pregnancy, pre-eclampsia/eclampsia, puerperium, autoimmune disorders and exposure to certain drugs [1,11-15]. Stoessl et al. [16] reported 2 cases of RCVS and severe intracranial haemorrhage in young women taking catecholaminergic agents. Henry et al. [13] reported RCVS following exposure to ergot derivatives. Rumbaugh et al. [14] presented cases of RCVS following illicit drug use, although the exact agent triggering the episodes could not be identified. Some of the drugs that have been reported as a risk factor for RCVS include selective serotonin reuptake inhibitors, triptans, cocaine, ecstasy, marijuana, amphetamine derivatives, cytotoxic drugs, ephedrine and pseudoephedrine $[1,17]$. In contrast, nifedipine withdrawal was reported to cause $\mathrm{TCH}$ in a 35-year-old woman with systemic lupus erythematous who was taking the drug as a treatment for HTN [18]. While the latter case [18] and our case were both associated with a history of autoimmune disorders, it is possible that a complex relationship between autoimmunity and nifedipine withdrawal was the culprit for RCVS. In addition, abrupt cessation of different types of CCBs has been reported to cause coronary artery vasospasm [19]. The underlying mechanism is poorly understood. However, one of the theories behind this phenomenon is that the use of CCBs causes calcium depletion in smooth muscle cells [20]. The high 


\section{Case Reports in Neurology}

Alanazy et al.: Reversible Cerebral Vasoconstriction Syndrome after Nifedipine Withdrawal

concentration of calcium in the extracellular space compared to the intracellular space causes calcium to follow the gradient and move to the intracellular space upon the abrupt withdrawal of CCBs [20]. This leads to depolarization and contraction of smooth muscle cells and, eventually, coronary vasospasm [20].

$\mathrm{TCH}$ is recognized as the most common presenting symptom in RCVS [8, 9]. Even though our patient's headache improved after 2 days, headache may persist for 2 weeks [8]. Our patient did not have any neurological findings upon presentation and developed them during the course of the hospital stay, which was similarly reported in the literature [1]. In a previous study, clinical worsening occurred after a median time of 2.5 days in $34 \%$ of the patients [7]. Of these patients, $40 \%$ developed permanent deficits [7]. Many complications of RCVS have been reported, including $\mathrm{SAH}$, intracerebral haemorrhage and seizure, with different proportions of 34, 20, and 17\%, respectively [9]. Moreover, infractions and haemorrhages have been observed in posterior regions of the brain, particularly watershed areas [9]. Therefore, a posterior reversible encephalopathy syndrome (PRES) pattern is consequently observed in some patients [9]. However, the prognosis remains favourable. In one study, all 67 patients showed complete resolution of arterial vasoconstriction over a period of 30-90 days [21]. Most patients recovered without deficits, and only $6 \%$ had a permanent neurological deficit [21]. RCVS recurrence has been reported in $8 \%$ of patients after approximately 2 years of followup [8].

Whereas the sensitivity of CT is high in SAH, it is not in RCVS [9, 22], which explains the initial normal head CT in our patient. In a study, CT and MRI were observed to be normal in $55 \%$ of patients upon presentation, while $81 \%$ later developed brain lesions [9]. Whether nimodipine, a CCB, effectively relieves the symptoms of RCVS [6, 8] or not [9] remains controversial. Several therapeutic agents have been tested, including magnesium sulphate, dantrolene and glucocorticoids. However, poor prognosis is observed following the administration of glucocorticoids $[1,9,23]$.

\section{Conclusions}

The sudden withdrawal of nifedipine is a potential trigger of RCVS. While further reports are required to confirm our observation, clinicians should include this possibility among the conditions that can trigger RCVS.

\section{Statement of Ethics}

The patient was informed of the purpose of the case presentation and gave her written informed consent for the publication of her case (including publication of images).

\section{Conflict of Interest Statement}

The authors declare no conflicts of interest. 


\section{Case Reports in Neurology}

\section{Funding Sources}

The authors would like to thank Deanship of Scientific Research at King Saud University for funding and supporting this research through DSR Scholarship support.

\section{Authorship Contributions}

Writing of the manuscript was primarily done by A. Alwadei, and Z.F. Alsaaran aided in the case report writing and interviewing the patient. M.H. Alanazy contributed to revising the manuscript and supervised the whole process of this report's production. F.A. Essbaiheen reviewed and provided the images. M.H. Alanazy, A. Alwadei and Z.F. Alsaaran revised the final version of the manuscript.

\section{References}

1 Mehdi A, Hajj-Ali RA. Reversible cerebral vasoconstriction syndrome: a comprehensive update. Curr Pain Headache Rep. 2014 Sep;18(9):443.

2 Sattar A, Manousakis G, Jensen MB. Systematic review of reversible cerebral vasoconstriction syndrome. Expert Rev Cardiovasc Ther. 2010 Oct;8(10):1417-21.

3 Ducros A, Fiedler U, Porcher R, Boukobza M, Stapf C, Bousser MG. Hemorrhagic manifestations of reversible cerebral vasoconstriction syndrome: frequency, features, and risk factors. Stroke. 2010 Nov;41(11):250511.

4 Cole AJ, Aubé M. Migraine with vasospasm and delayed intracerebral hemorrhage. Arch Neurol. 1990 Jan;47(1):53-6.

5 Liu HY, Fuh JL, Lirng JF, Chen SP, Wang SJ. Three paediatric patients with reversible cerebral vasoconstriction syndromes. Cephalalgia. 2010 Mar;30(3):354-9.

6 Chen SP, Fuh JL, Lirng JF, Chang FC, Wang SJ. Recurrent primary thunderclap headache and benign CNS angiopathy: spectra of the same disorder? Neurology. 2006 Dec;67(12):2164-9.

7 Katz BS, Fugate JE, Ameriso SF, Pujol-Lereis VA, Mandrekar J, Flemming KD, et al. Clinical worsening in reversible cerebral vasoconstriction syndrome. JAMA Neurol. 2014 Jan;71(1):68-73.

8 Chen SP, Fuh JL, Wang SJ. Reversible cerebral vasoconstriction syndrome: an under-recognized clinical emergency. Ther Adv Neurol Disord. 2010 May;3(3):161-71.

9 Singhal AB, Hajj-Ali RA, Topcuoglu MA, Fok J, Bena J, Yang D, et al. Reversible cerebral vasoconstriction syndromes: analysis of 139 cases. Arch Neurol. 2011 Aug;68(8):1005-12.

10 Hyde-Rowan MD, Roessmann U, Brodkey JS. Vasospasm following transsphenoidal tumor removal associated with the arterial changes of oral contraception. Surg Neurol. 1983 Aug;20(2):120-4.

11 Will AD, Lewis KL, Hinshaw DB Jr, Jordan K, Cousins LM, Hasso AN, et al. Cerebral vasoconstriction in toxemia. Neurology. 1987 Sep;37(9):1555-7.

12 Bogousslavsky J, Despland PA, Regli F, Dubuis PY. Postpartum cerebral angiopathy: reversible vasoconstriction assessed by transcranial Doppler ultrasounds. Eur Neurol. 1989;29(2):102-5.

13 Henry PY, Larre P, Aupy M, Lafforgue JL, Orgogozo JM. Reversible cerebral arteriopathy associated with the administration of ergot derivatives. Cephalalgia. 1984 Sep;4(3):171-8.

14 Rumbaugh CL, Bergeron RT, Fang HC, McCormick R. Cerebral angiographic changes in the drug abuse patient. Radiology. 1971 Nov;101(2):335-44.

15 Ducros A. Reversible cerebral vasoconstriction syndrome. Lancet Neurol. 2012 Oct;11(10):906-17.

16 Stoessl AJ, Young GB, Feasby TE. Intracerebral haemorrhage and angiographic beading following ingestion of catecholaminergics. Stroke. 1985 Jul-Aug;16(4):734-6.

17 Oz O, Demirkaya S, Bek S, Eroğlu E, Ulaş UH, Odabaşi Z. Reversible cerebral vasoconstriction syndrome: case report. J Headache Pain. 2009 Aug;10(4):295-8.

18 Chung SW, Lee KM, Heo SH, Ra R, Hong SJ, Yang HI, et al. A systemic lupus erythematosus patient with thunderclap headache: reversible cerebral vasoconstriction syndrome. Lupus. 2019 Jun;28(7):898-902.

19 Engelman RM, Hadji-Rousou I, Breyer RH, Whittredge P, Harbison W, Chircop RV. Rebound vasospasm after coronary revascularization in association with calcium antagonist withdrawal. Ann Thorac Surg. 1984 Jun;37(6):469-72.

20 Peeters LE, den Uil CA, Feyz L, van den Bemt PM, Daemen J, Versmissen J. Acute calcium channel blocker withdrawal-induced cardiac arrest. Neth J Med. 2019 Dec;77(9):341-3. 
Case Reports in Neurology

\begin{tabular}{l|l}
\hline Case Rep Neurol 2020;12:440-446 \\
\hline DOI: 10.1159/000511204 & $\begin{array}{l}\text { @ 2020 The Author(s). Published by S. Karger AG, Basel } \\
\text { www.karger.com/crn }\end{array}$ \\
\hline
\end{tabular}

Alanazy et al.: Reversible Cerebral Vasoconstriction Syndrome after Nifedipine Withdrawal

21 Ducros A, Boukobza M, Porcher R, Sarov M, Valade D, Bousser MG. The clinical and radiological spectrum of reversible cerebral vasoconstriction syndrome. A prospective series of 67 patients. Brain. 2007 Dec;130(Pt 12):3091-101.

22 Dubosh NM, Bellolio MF, Rabinstein AA, Edlow JA. Sensitivity of early brain computed tomography to exclude aneurysmal subarachnoid hemorrhage: a systematic review and meta-analysis. Stroke. 2016 Mar;47(3):750-5.

23 Muehlschlegel S, Rordorf G, Bodock M, Sims JR. Dantrolene mediates vasorelaxation in cerebral vasoconstriction: a case series. Neurocrit Care. 2009;10(1):116-21.
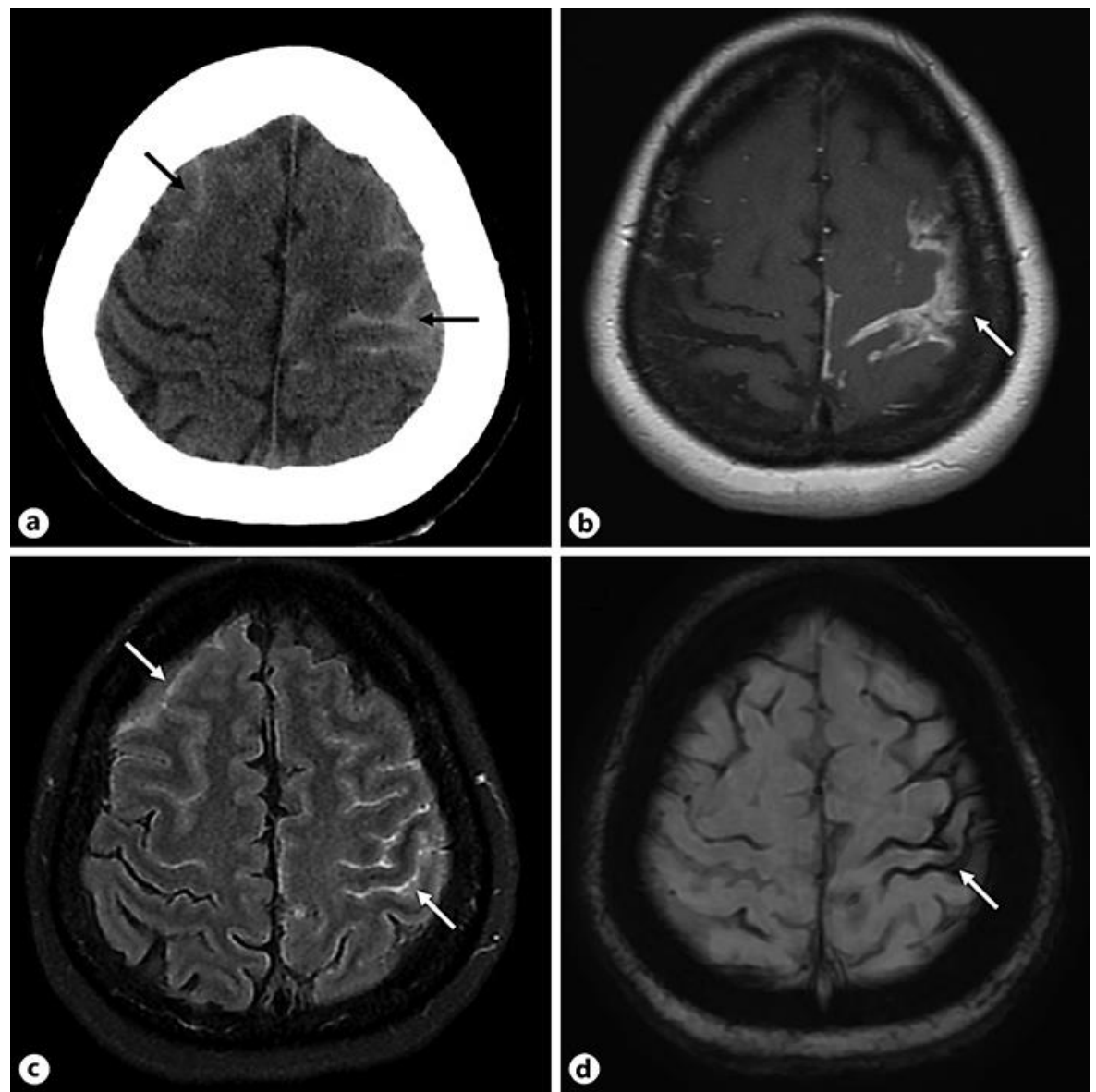

Fig. 1. Selected axial images at the level of the vertex showing bilateral convexal SAH (arrows). This appears hyperdense on non-enhanced CT (a), hyperintense on T1- and FLAIR-weighted MR images (b and $\mathbf{c}$ ) and blooming on the susceptibility-weighted image (d). 
Case Reports in Neurology
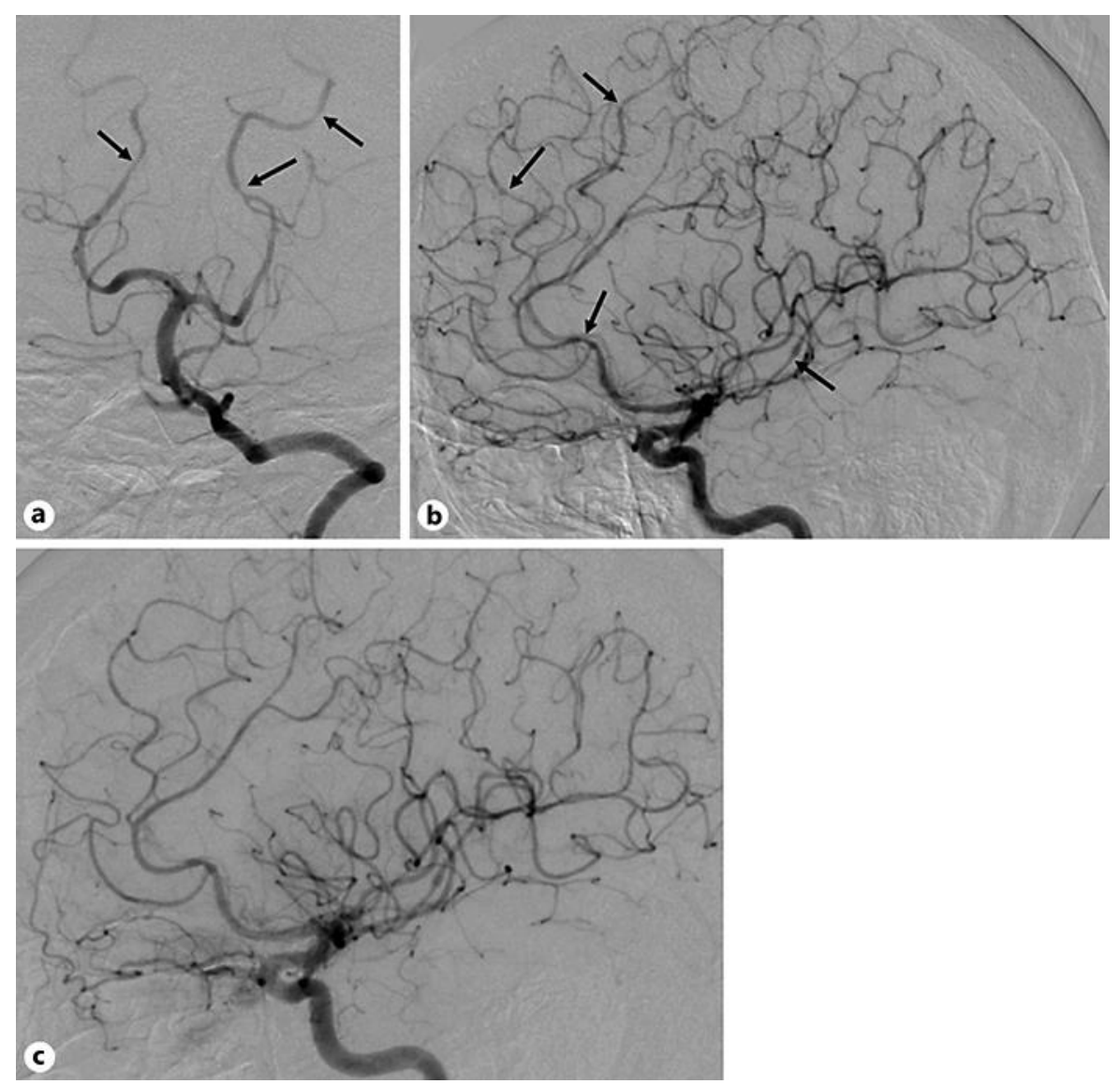

Fig. 2. Digital subtracted images from a conventional cerebral angiogram showing multiple areas of arterial narrowing followed by areas of dilatation in the posterior (a) and anterior (b) circulation (arrows). Interval improvement is seen (c compared to $\mathbf{b}$ ) after the administration of an intra-arterial CCB. 